\title{
Hospitalisation for RSV infection in ex-preterm infants-implications for use of RSV immune globulin
}

\author{
Mark Thomas, Alison Bedford-Russell, Mike Sharland
}

\begin{abstract}
Background-Respiratory syncytial virus (RSV) specific immune globulin is now being marketed for prevention of RSV infection in ex-preterm infants. However, there are no published UK data on the morbidity or mortality from RSV in these infants.

Aims-To determine the morbidity and mortality from RSV infection in a cohort of infants previously treated at a regional neonatal unit, and compare the cost of hospitalisation for RSV with the potential cost of administering RSV immune globulin (RSV-IG) prophylaxis.

Methods-Infants born at a gestation of less than 32 weeks were studied. Details of admissions for respiratory illness in the first two years of life were collected from hospital records, referring hospitals, and general practitioners.

Results-Data on 82 infants were collected. Up to three RSV seasons were encountered. The hospitalisation rate for confirmed RSV infection for the first season encountered was $4 \%$. Rates of ward and paediatric intensive care unit admission were higher for infants with chronic lung disease. There were no deaths from RSV. RSV-IG would not have been cost effective for most infants.

Conclusion-The morbidity and mortality rates from RSV observed in this group do not support the widespread introduction of RSV-IG prophylaxis for ex-preterm infants.

(Arch Dis Child 2000;83:122-127)
\end{abstract}

Keywords: respiratory syncytial virus; RSV prophylaxis; palivizumab; cost effectiveness

Neonatal Unit, St George's Hospital, Blackshaw Road, London SW17 0QT, UK $M$ Thomas

A Bedford-Russell

Paediatric Infectious Diseases Unit, St George's Hospital M Sharland

Correspondence to: Dr Bedford-Russell email:

alison.bedford-russell@ ccmail.stgh-tr.sthames.nhs.uk

Accepted 11 April 2000
Respiratory syncytial virus (RSV) is an important cause of respiratory tract infection in infancy, most commonly causing bronchiolitis. Preterm infants, especially those with chronic lung disease (CLD), are thought to be susceptible to more severe respiratory illness from RSV, compared with healthy term infants. ${ }^{12}$ However, there are no published UK data on the morbidity and mortality from RSV infection in preterm infants. In particular, there are no published data on readmission rates to paediatric wards and intensive care units, critical in cost effectiveness analyses.

Currently there is no commercially available vaccine against RSV. ${ }^{3}$ However, two preparations have been approved by the Food and Drug Administration (FDA) in the USA for passive protection against RSV in high risk infants.

RSV intravenous immune globulin (RSVIVIG, Respigam, MedImmune Inc.) is prepared from donors selected for high serum titres of RSV neutralising antibody. It is administered once per month by intravenous infusion at a dose of $750 \mathrm{mg} / \mathrm{kg}$, just prior to and during the RSV season. Palivizumab (Synagis, MedImmune Inc./Abbott Laboratories) is a monoclonal antibody preparation directed against the F glycoprotein of RSV. It is also administered once per month, just prior to and during the RSV season, but by intramuscular injection at a dose of $15 \mathrm{mg} / \mathrm{kg}$. Palivizumab is now available in the UK. Its licensed indication is for the "... prevention of serious lower respiratory tract disease requiring hospitalisation caused by RSV in children who are born at 35 weeks of gestation or less and who are less than 6 months of age at the onset of the RSV season, or in children who are less than 2 years of age and had required treatment for bronchopulmonary dysplasia within the last six months".

The American Academy of Pediatrics (AAP) has made recommendations for the use of these two preparations (see box). ${ }^{45}$ The Academy suggests that practitioners use RSV rehospitalisation data from their own region when making decisions on whether to use RSV prophylaxis. Therefore before the widespread introduction of these preparations in the UK, existing morbidity and mortality from RSV in preterm infants should be determined. This study

AAP guidelines for use of palivizumab or RSV-IVIG

Palivizumab or RSV-IVIG prophylaxis should be considered for:

- Infants and children younger than 2 years of age with CLD who are receiving oxygen

- Infants and children younger than 2 years of age with CLD who have required oxygen within six months of the start of the RSV season (this was subsequently widened to include other "medical therapies" such as bronchodilators, corticosteroids, or diuretics)

- Infants born at less than 29 weeks gestation, who do not meet the first two criteria, up to 12 months of age

- Infants born at 29-32 weeks gestation, who do not meet the first two criteria, up to 6 months of age 
presents the data from one regional neonatal unit for preterm infants born in 1995 .

When new therapies become available in the medical marketplace, they have the potential to increase or reduce overall costs for the healthcare provider. This study includes a cost analysis for use of RSV immune globulin (RSV-IG), and a survey of neonatal units in the Thames regions to examine differences in attitude regarding introduction of this new therapy.

\section{Methods}

RSV HOSPITALISATION DATA

All neonates under 32 weeks gestation admitted to St George's Hospital Neonatal Unit (SGH NNU) between 1 January and 31 December 1995 were identified from the unit register. Only those neonates admitted for medical neonatal intensive care within the first week of life were studied, as this group would have the greatest follow up details available; neonates admitted purely for surgical procedures such as Broviac line insertion normally have follow up at their referring hospital only. A total of 128 neonates fitted the study criteria, 99 of which survived to discharge and formed the study group.

Data were collected from SGH case notes on:

(a) Birth gestation

(b) Corrected age at discharge home and on 1 October 1995, 1996, 1997

(c) Presence of CLD (supplemental oxygen dependency at 36 weeks post-conceptual age)

(d) For infants with CLD, requirement for home oxygen during each RSV season

(e) For infants with CLD, requirement for supplemental oxygen within six months of each RSV season

(f) Number of admissions for respiratory illness in each RSV season (October to March) encountered at a corrected age of less than 2 years.

Where data on (b) to (e) above were not present in case notes (usually babies discharged back to their referring district general hospital), the referring hospital was contacted for the information. SGH NNU policy is to follow up all babies born at less than 32 weeks gestation at 6 months, 1 year, 2 years, and 4 years corrected age. Parents are routinely asked about any admissions since their previous outpatient appointment. Where data on (f) above were not present in the case notes (children who did not attend for follow up or question regarding admissions not asked), the child's general practitioner (GP) was contacted by individualised letter and asked to list any admissions to hospital that had occurred for any respiratory illness.

For each admission with respiratory illness, the following data were obtained:

(a) Diagnosis

(b) Days on ward

(c) Days on paediatric intensive care unit (PICU)

(d) Days on mechanical ventilation

(e) Days on continuous positive airway pressure (CPAP) (f) Days in head box/nasal cannula oxygen

(g) Died? Y/N

(h) RSV positive? Y/N/unknown.

These data were obtained from SGH case notes where the child was readmitted to SGH with respiratory illness. Where admission was to a different hospital, the admitting consultant was asked to provide the data from the respective hospital's case notes. RSV status was determined by nasopharyngeal aspirate (NPA) and standard RSV antigen detection methods.

COST CALCULATIONS

The potential cost of administering RSV-IG prophylaxis to the study group of infants was calculated for palivizumab, as this is the only preparation likely to be commercially available in the UK. One $100 \mathrm{mg}$ vial of palivizumab costs $£ 706$ (source: Abbott Laboratories). The recommended dose regimen, and that used in the IMpact trial, is $15 \mathrm{mg} / \mathrm{kg} / \mathrm{month}$ of the RSV season. One $100 \mathrm{mg}$ vial will treat one infant up to a weight of $6.6 \mathrm{~kg}$. In practice, some larger infants would require more than one vial per month. Equally it would be possible to treat an infant weighing less than $3.3 \mathrm{~kg}$ with a $50 \mathrm{mg}$

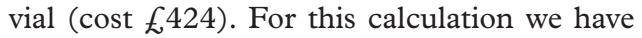
assumed one $100 \mathrm{mg}$ vial per infant per month, making cost per season $£ 4236$ per infant. This is based on six months treatment as the RSV season in the UK lasts from October to March. ${ }^{6}$ We anticipate that palivizumab could be administered by a community nurse, thereby reducing the chance of an infant contracting RSV on entering the paediatric hospital environment. The costs of a single home visit are difficult to quantify and have not been included in the analysis. The potential cost of prophylaxis was calculated for infants in each category of the AAP guidelines and compared with actual cost of hospitalisation for the infants filling the criteria in each group.

Hospitalisation costs were estimated for each infant admitted with RSV positive or RSV unknown bronchiolitis or pneumonia. For each admission, the number of days spent on the paediatric ward and, if applicable, in the paediatric intensive care unit were determined from the hospital notes. For each PICU day, level of care (according to Paediatric Intensive Care Society Standards for Paediatric Intensive Care, 1996) was ascertained from the clinical details available. An estimate of cost for the particular admission was then made by combining this information with current SGH costs per day for the general paediatric ward and levels 1,2, and 3 of paediatric intensive care.

SURVEY OF NEONATAL UNITS IN NORTH AND SOUTH THAMES REGIONS

A questionnaire was sent to one consultant paediatrician of each neonatal unit represented on the Thames Regional Perinatal Group (TRPG). Forty eight questionnaires were sent.

\section{Results}

RSV HOSPITALISATION DATA

A total of 99 infants filled the study entry criteria. Seventeen had incomplete data available and were therefore excluded from the final 
Table 1 First RSV season encountered

\begin{tabular}{|c|c|c|c|c|c|c|c|c|c|c|}
\hline Infant category & $\begin{array}{l}\text { Total } \\
\text { babies } \\
\text { studied }\end{array}$ & $\begin{array}{l}\text { Admitted with } \\
\text { LRTI: } R S V \\
\text { positive }\end{array}$ & $\%$ & $\begin{array}{l}\text { Admitted with } \\
\text { LRTI: } R S V \\
\text { unknown }\end{array}$ & $\%$ & $\begin{array}{l}\text { Total } \\
\text { ward } \\
\text { days }\end{array}$ & $\begin{array}{l}\text { Total } \\
\text { PICU } \\
\text { days }\end{array}$ & $\begin{array}{l}\text { Total } \\
\text { vent } \\
\text { days }\end{array}$ & $\begin{array}{l}\text { Total } \\
\text { CPAP } \\
\text { days }\end{array}$ & $\begin{array}{l}\text { Total } \\
\text { oxygen } \\
\text { days }\end{array}$ \\
\hline $\begin{array}{l}\text { 1. Infants with } \\
\text { CLD on home } \\
\text { oxygen }\end{array}$ & 7 & 1 & 14 & 0 & 0 & 18 & 20 & 18 & 0 & 14 \\
\hline $\begin{array}{l}\text { 2. Infants with } \\
\text { CLD who had } \\
\text { stopped oxygen } \\
\text { in prior } 6 \\
\text { months }\end{array}$ & 27 & 2 & 7 & 2 & 7 & 16 & 6 & 4 & 1 & 11 \\
\hline $\begin{array}{l}\text { 3. Infants not in } \\
\text { group } 1 \text { or } 2 \text {, } \\
<29 \text { weeks } \\
\text { gestation }\end{array}$ & 7 & 0 & 0 & 0 & 0 & - & - & - & - & - \\
\hline $\begin{array}{l}\text { 4. Infants not in } \\
\text { group } 1 \text { or } 2 \text {, } \\
29-32 \text { weeks } \\
\text { gestation }\end{array}$ & 41 & 0 & 0 & 1 & 2 & 1 & 0 & 0 & 0 & 0 \\
\hline Total & 82 & 3 & 4 & 3 & 4 & 35 & 26 & 22 & 1 & 25 \\
\hline
\end{tabular}

analysis. Reasons for incomplete data were: change of or non-responding GP (11/17), nonresponding district general hospital (4/17), and lost hospital notes (2/17). One of the excluded infants died from SIDS; RSV was not implicated at postmortem examination. The Office for National Statistics was contacted to determine the status of the 16 remaining excluded infants, to ensure that these infants had not died. Fifteen of these infants were confirmed as alive and registered with a GP. The remaining excluded infant had been adopted and could not be traced. The median gestational age for the excluded babies was similar to that for the study babies (28.3 and 28.5 weeks respectively).

All 82 infants encountered two RSV seasons before reaching a corrected age of 2 years. Forty of the 82 encountered a third RSV season before reaching this age. For each season encountered, the infants were categorised to correspond with the AAP guidelines on use of RSV-IG. The first season for some infants was 1995-96 and for others 1996-97, and so on for the subsequent seasons. Tables 1 , 2 , and 3 show the hospitalisation rates for RSV positive and RSV unknown lower respiratory tract infection (LRTI) for each season encountered. Total ward, PICU, ventilator, CPAP, and additional oxygen days are also shown for these admissions. The overall hospitalisation rate for the first season encountered was 8\% (RSV positive LRTI 4\%; RSV unknown LRTI 4\%) No infant died during any of these admissions. Eight infants' admissions for respiratory illness have not been included in the results tables. These admissions were either for RSV negative LRTI, or for respiratory illness other than bronchiolitis or pneumonia where an NPA had not been considered appropriate by the attending paediatrician.

\section{COST ANALYSIS}

Table 4 presents a comparison of potential cost of palivizumab administration with actual cost of hospitalisation for RSV positive or RSV unknown LRTI. The numbers in each group are slightly different from those in the hospitalisation tables 1, 2, and 3, as some infants would be eligible for prophylaxis for more than one RSV season.

SURVEY OF NEONATAL UNITS IN NORTH AND SOUTH THAMES REGIONS

Thirty nine questionnaires were returned (response rate $81 \%$ ). Level 3 unit response rate was $100 \%$. A total of 161 infants were discharged from these units on home oxygen during a 12 month period 1997-98. No unit used RSV-IG prophylaxis during the RSV season 1997-98. Table 5 shows individual neonatal unit policies for the use of RSV-IG in forthcoming seasons, according to level of unit

Table 2 Second RSV season encountered

\begin{tabular}{|c|c|c|c|c|c|c|c|c|c|c|}
\hline Infant category & $\begin{array}{l}\text { Total } \\
\text { babies } \\
\text { studied }\end{array}$ & $\begin{array}{l}\text { Admitted with } \\
\text { LRTI: RSV } \\
\text { positive }\end{array}$ & $\%$ & $\begin{array}{l}\text { Admitted with } \\
\text { LRTI: RSV } \\
\text { unknown }\end{array}$ & $\%$ & $\begin{array}{l}\text { Total } \\
\text { ward } \\
\text { days }\end{array}$ & $\begin{array}{l}\text { Total } \\
\text { PICU } \\
\text { days }\end{array}$ & $\begin{array}{l}\text { Total } \\
\text { vent } \\
\text { days }\end{array}$ & $\begin{array}{l}\text { Total } \\
\text { CPAP } \\
\text { days }\end{array}$ & $\begin{array}{l}\text { Total } \\
\text { oxygen } \\
\text { days }\end{array}$ \\
\hline $\begin{array}{l}\text { 1. Infants with } \\
\text { CLD on home } \\
\text { oxygen }\end{array}$ & 1 & 0 & 0 & 0 & 0 & - & - & - & - & - \\
\hline $\begin{array}{l}\text { 2. Infants with } \\
\text { CLD who had } \\
\text { stopped oxygen } \\
\text { in prior } 6 \\
\text { months }\end{array}$ & 4 & 0 & 0 & 0 & 0 & - & - & - & - & - \\
\hline $\begin{array}{l}\text { 3. Infants not in } \\
\text { group } 1 \text { or } 2 \text {, } \\
<29 \text { weeks } \\
\text { gestation }\end{array}$ & 33 & 0 & 0 & 1 & 3 & 1 & 0 & 0 & 0 & 0 \\
\hline $\begin{array}{l}\text { 4. Infants not in } \\
\text { group } 1 \text { or } 2 \text {, } \\
29-32 \text { weeks } \\
\text { gestation }\end{array}$ & 44 & 0 & 0 & 0 & 0 & - & - & - & - & - \\
\hline Total & 82 & 0 & 0 & 1 & 1 & 1 & 0 & 0 & 0 & 0 \\
\hline
\end{tabular}


Table 3 Third RSV season encountered

\begin{tabular}{|c|c|c|c|c|c|c|c|c|c|c|}
\hline Infant category & $\begin{array}{l}\text { Total } \\
\text { babies } \\
\text { studied }\end{array}$ & $\begin{array}{l}\text { Admitted with } \\
\text { LRTI: RSV } \\
\text { positive }\end{array}$ & $\%$ & $\begin{array}{l}\text { Admitted with } \\
\text { LRTI: RSV } \\
\text { unknown }\end{array}$ & $\%$ & $\begin{array}{l}\text { Total } \\
\text { ward } \\
\text { days }\end{array}$ & $\begin{array}{l}\text { Total } \\
\text { PICU } \\
\text { days }\end{array}$ & $\begin{array}{l}\text { Total } \\
\text { vent } \\
\text { days }\end{array}$ & $\begin{array}{l}\text { Total } \\
\text { CPAP } \\
\text { days }\end{array}$ & $\begin{array}{l}\text { Total } \\
\text { oxygen } \\
\text { days }\end{array}$ \\
\hline $\begin{array}{l}\text { 1. Infants with } \\
\text { CLD on home } \\
\text { oxygen }\end{array}$ & 0 & 0 & - & 0 & - & - & - & - & - & - \\
\hline $\begin{array}{l}\text { 2. Infants with } \\
\text { CLD who had } \\
\text { stopped oxygen } \\
\text { in prior } 6 \\
\text { months }\end{array}$ & 0 & 0 & - & 0 & - & - & - & - & - & - \\
\hline $\begin{array}{l}\text { 3. Infants not in } \\
\text { group } 1 \text { or } 2 \text {, } \\
<29 \text { weeks } \\
\text { gestation }\end{array}$ & 15 & 0 & 0 & 0 & 0 & - & - & - & - & - \\
\hline $\begin{array}{l}\text { 4. Infants not in } \\
\text { group } 1 \text { or } 2 \text {, } \\
29-32 \text { weeks } \\
\text { gestation }\end{array}$ & 25 & 0 & 0 & 0 & 0 & - & - & - & - & - \\
\hline Total & 40 & 0 & 0 & 0 & 0 & 0 & 0 & 0 & 0 & 0 \\
\hline
\end{tabular}

(British Association of Perinatal Medicine classification).

\section{Discussion}

A number of trials have been conducted to determine the effectiveness of the new RSV prophylaxis preparations. ${ }^{7-10}$ The PREVENT study showed an overall $41 \%$ reduction in hospitalisation for RSV when RSV-IVIG was administered to 250 infants fitting the AAP criteria for treatment. ${ }^{9}$ However, RSV-IVIG has several disadvantages compared with the newer palivizumab preparation which make its widespread use in the UK unlikely. These include risk of fluid overload, requirement of intravenous cannulation and infusion over sev-

Table 4 Comparison of potential cost of palivizumab administration with actual cost of hospitalisation for RSV positive or RSV unknown LRTI

\begin{tabular}{lllll}
\hline Treatment category & $\begin{array}{l}\text { Number of } \\
\text { infants }\end{array}$ & Cost of prophylaxis & $\begin{array}{l}\text { Number of } \\
\text { admissions }\end{array}$ & $\begin{array}{l}\text { Hospitalisation } \\
\text { cost }\end{array}$ \\
\hline $\begin{array}{l}\text { 1. Infants <2 y with } \\
\text { CLD on home } \\
\text { oxygen }\end{array}$ & 8 & $£ 33888$ & 1 & $£ 30072$ \\
$\begin{array}{l}\text { 2. Infants <2 y with } \\
\text { CLD who have } \\
\text { stopped oxygen in } \\
\text { prior 6 months }\end{array}$ & 31 & $£ 131316$ & 4 & $£ 13644$ \\
$\begin{array}{l}\text { 3. Infants <1 y born at } \\
\text { <29 weeks gestation }\end{array}$ & 7 & $£ 29652$ & & $£ 0$ \\
$\begin{array}{l}\text { 4. Infants <6 months } \\
\text { born at 29-32 weeks } \\
\text { gestation }\end{array}$ & 41 & $£ 173676$ & 1 & $£ 472$ \\
\begin{tabular}{l} 
All \\
\hline
\end{tabular} & 87 & $£ 368532$ & 6 & $£ 44188$ \\
\hline
\end{tabular}

Table 5 Individual neonatal unit policies for the use of RSV-IG in forthcoming seasons, according to level of unit (British Association of Perinatal Medicine classification)

\begin{tabular}{|c|c|c|c|c|c|c|}
\hline \multirow[b]{2}{*}{$\begin{array}{l}\text { Individual neonatal unit } \\
\text { policy for use of RSV } \\
\text { prophylaxis }\end{array}$} & \multicolumn{6}{|c|}{ Neonatal unit classification } \\
\hline & $\begin{array}{l}\text { Level I } \\
\text { Number }\end{array}$ & $\%$ & $\begin{array}{l}\text { Level II } \\
\text { Number }\end{array}$ & $\%$ & $\begin{array}{l}\text { Level III } \\
\text { Number }\end{array}$ & $\%$ \\
\hline RSV-IG in no infants & 6 & 55 & 16 & 70 & 4 & 80 \\
\hline $\begin{array}{l}\text { RSV-IG on an } \\
\text { individualised basis }\end{array}$ & 0 & 0 & 0 & 0 & 1 & 20 \\
\hline $\begin{array}{l}\text { RSV-IG in infants }<2 \text { y } \\
\text { with CLD on home } \\
\text { oxygen }\end{array}$ & 3 & 27 & 5 & 22 & 0 & 0 \\
\hline $\begin{array}{l}\text { RSV-IG in infants }<2 \text { y } \\
\text { with CLD who have } \\
\text { received oxygen within } 6 \\
\text { months of start of RSV } \\
\text { season }\end{array}$ & 2 & 18 & 2 & 9 & 0 & 0 \\
\hline $\begin{array}{l}\text { RSV-IG in all infants }<32 \\
\text { weeks gestation up to } \\
\text { corrected age } 1 \mathrm{y}\end{array}$ & 0 & 0 & 0 & 0 & 0 & 0 \\
\hline Total & 11 & 100 & 23 & 100 & 5 & 100 \\
\hline
\end{tabular}

eral hours, possibility of transmission of infection from IVIG donors, and disruption of the routine childhood vaccination schedule. The IMpact study was a multicentre international phase III trial undertaken to evaluate the safety and effectiveness of monthly administration of palivizumab as prophylaxis against serious RSV illness in high risk children. ${ }^{10}$ Children were eligible for recruitment if they were either 35 weeks gestation or less and 6 months of age or younger at the onset of the RSV season, or if they were 24 months or younger with a clinical diagnosis of CLD requiring ongoing medical treatment during the six months before the onset of the RSV season. The latter medical treatments comprised supplemental oxygen, steroids, bronchodilators, or diuretics, so the group was clearly heterogeneous with respect to severity of CLD. Palivizumab was administered to 1002 children and placebo to 500 children. Prophylaxis resulted in a 55\% reduction in admission to hospital as a result of RSV infection, when the two recruitment groups were combined. However, the greatest reduction in admission rate $(78 \%)$ occurred in children who were born at less than 35 weeks gestation but without CLD - that is, those at least risk of severe RSV illness. Children with CLD had a smaller reduction in admission rate $(39 \%)$. Furthermore, the results of the study were expressed as relative risk reduction rather than absolute risk reduction, thereby exaggerating the treatment benefit. ${ }^{11}$ Neither the PREVENT nor the IMpact study showed a reduction in either days spent on PICU or requirement for mechanical ventilation for infants receiving prophylaxis, and neither study showed a reduction in mortality from RSV in these infants.

The incidence of hospitalisation for RSV among preterm infants reported in previous studies from North America varies between $2.8 \%$ and $37 \% .{ }^{17-10}{ }^{12-14}$ The higher rates come either from studies looking only at preterm infants with underlying pulmonary or cardiac problems or from the control arms of randomised controlled trials for RSV-IG. These studies may not be representative of a typical neonatal unit preterm population. A population based study from northern California published recently reported a similar overall rate of hospi- 
talisation to our study. ${ }^{14}$ The study also showed a higher rate of hospitalisation in infants who were oxygen dependent at 28 days of life, but was not able to report specific hospitalisation rates for infants with CLD on home oxygen or for infants with CLD who had come off supplementary oxygen in the six months before the RSV season (the first two categories of the AAP guidelines). Among 1721 infants with full follow up, there were no deaths from RSV, as in our study. The only previous UK study looking at hospitalisation for RSV included all infants, not only those born preterm, and found a national admission rate of $3 \% .^{15}$

Our study suggests that the first RSV season encountered accounts for most of the morbidity seen from RSV. This is in accordance with a study of 427 high risk infants by Wang et al which showed a significant decrease in frequency of RSV-LRTI and RSV hospitalisation with increasing age, with a major drop in those over 1 year. ${ }^{12}$

Considering the relatively low rates of hospitalisation for RSV found among preterm infants without recently treated chronic lung disease in the present and other studies, one must question the broadness of the AAP guidelines and the UK licensed indications detailed above in terms of the cost of RSV-IG prophylaxis. The cost information presented here is not intended to be a formal cost-benefit analysis which should take account of societal costs such as loss of parental working days and which is usually presented in terms of cost per life-year saved. Our study population is too small to perform a meaningful analysis of this type. Instead, we present a cost comparison from the perspective of a large regional neonatal unit. The potential cost of palivizumab prophylaxis for the infants less than 2 years of age with CLD on home oxygen was similar to the high cost of hospitalisation for the one infant admitted with RSV-LRTI in this group. For all other groups, the potential cost of palivizumab would have been far higher than the actual cost of hospitalisation for RSV. Our comparison is biased in favour of prophylaxis for the following reasons. Firstly, we have included infants admitted with RSV unknown LRTI in the hospitalisation costs; many of these infants were probably not suffering from RSV. Secondly, we have not included costs involved in palivizumab administration (for example, paediatric community nursing). Finally, we have not taken into account the fact that palivizumab will not prevent all admissions of cases with RSV.

Hall et al emphasise the importance of performing a local cost analysis before introducing RSV prophylaxis in a designated area. ${ }^{16}$ They acknowledge that most analyses will not include costs or benefits other than those directly encountered by the healthcare provider. They identify the important variables in such analyses as local rehospitalisation rate for RSV infection among ex-preterm infants (with and without CLD), and local average cost of a hospital admission for RSV for these groups of infants. They also suggest collecting these data for different gestational ages, as those infants who are relatively less preterm are likely to exhibit less morbidity from RSV. We have pre- sented our data in categories corresponding to AAP guidelines rather than purely gestational age. This highlights the increased morbidity seen in the two groups with CLD compared with those without. In fact one of the two infants requiring ventilation for RSV was 29 weeks gestation at birth, not extremely preterm, but did have CLD.

Two cost effectiveness analyses for palivizumab use in the USA were published in 1999. ${ }^{17}{ }^{18}$ Joffe et al have the advantage of using their population based RSV rehospitalisation data in their calculations. ${ }^{14} 18$ They present their cost effectiveness analysis for palivizumab firstly in terms of cost per RSV hospitalisation averted. This varies from $\$ 12000$ to $\$ 420000$ depending on gestational age, oxygen dependency at 28 days of life, and time of discharge from the NICU relative to the RSV season. They also present their analysis in terms of cost per life-year saved. However, as mentioned in the accompanying commentary, ${ }^{19}$ the authors make the assumption that because hospitalisation is reduced by $55 \%$ in the IMpact trial, it follows that mortality would be reduced by a similar rate. There is no evidence of a reduction in mortality from RSV in either the IMpact trial nor any other trial of RSV-IG and therefore in a cost-benefit analysis there are no life-years saved by prophylaxis.

In summary, no previous study has conclusively shown cost effectiveness for palivizumab. Our study suggests that treating infants with CLD on home oxygen would be relatively cost effective compared with other infants, although an incremental outlay may still be required. It seems likely that treating infants who are not on home oxygen would involve very large monetary outlay for little cost saving. Within the Thames regions, level 3 neonatal units are at present either not using palivizumab at all or restricting its use to selected very high risk infants. Based on the available research this would seem a sensible position to adopt. Even limiting palivizumab to all infants discharged on home oxygen, for the first RSV season encountered only, would cost in excess of $£ 682000$ for infants in the Thames regions. Further prospective randomised controlled trials to investigate cost-benefit are unlikely. The rise and fall of ribavarin treatment for RSV infection reminds us that the paediatrician's need to "do something" based on limited trial evidence must be tempered with detailed postmarketing surveillance. Palivizumab is moderately effective but very expensive, and has been referred to the National Institute for Clinical Excellence (see footnote). Further prospective data on RSV readmission rates among expreterm infants with severe CLD are required, along with prospective audit data on the use, cost, and benefit of palivizumab in the UK.

\section{FOOTNOTE ON NICE}

The National Institute for Clinical Excellence (NICE) was set up as a Special Health Authority on 1 April 1999 and as such it is a part of the National Health Service (NHS). Its aim is to provide the NHS (patients, health professionals, and the public) in England and Wales with 
guidance on current "best practice". This guidance will cover both individual health technologies and the clinical management of specific conditions.

The authors wish to thank Dr James Sedgwick for his help with the database design and data analysis.

1 Groothius JR, Gutierrez KM, Lauer BA. Respiratory syncytial virus infection in children with bronchopulmonary dystial virus infection in children with
plasia. Pediatrics $1988 ; 82: 199-203$.

2 Cunningham CK, McMillan JA, Gross SJ. Rehospitalization for respiratory illness in infants less than 32 weeks' gestation. Pediatrics 1991;88:527-32.

3 Karron RA, Ambrosino DM. Respiratory syncytial virus vaccines. Pediatr Infect Dis f 1998;17:919-20.

4 American Academy of Pediatrics, Committee on Infectious Diseases and Committee on Fetus and Newborn. Respiratory syncytial virus immune globulin intravenous: indications for use. Pediatrics 1997;99:645-50

5 American Academy of Pediatrics, Committee on Infectious Diseases and Committee on Fetus and Newborn. Prevention of respiratory syncytial virus infections: indications for the use of palivizumab and update on the use of RSV-IGIV. the use of palivizumab and upda

6 Public Health Laboratory Service Communicable Disease Surveillance Centre. Laboratory Reports to CDSC of Infections Due to Respiratory Syncytial Virus in England and Wales. Personal communication, Nichola Goddard, and Wales. Personal comm

7 Groothius JR, Simoes EAF, Levin MJ, et al. Prophylactic administration of respiratory syncytial virus immune globulin to high-risk infants and young children. $N$ Engl $\mathcal{F}$ Med 1993;329:1524-30

8 Groothius JR, Simoes EAF, Hemming VG. Respiratory syncytial virus infection in preterm infants and the protective effects of RSV immune globulin. Pediatrics 1995;95:463-7.
9 The PREVENT Study Group. Reduction of respiratory syncytial virus hospitalization among premature infants and infants with bronchopulmonary dysplasia using respiratory syncytial virus immune globulin prophylaxis. Pediatrics 1997;99:93-9.

10 The IMpact-RSV Study Group. Palivizumab, a humanized respiratory syncytial virus monoclonal antibody, reduces hospitalization from respiratory syncytial virus infection in high-risk infants. Pediatrics 1998:102:531-7.

11 Nicholl RM. RSV prevention. Arch Dis Child 2000;82:88.

12 Wang EEL, Law BJ, Robinson JL, et al. PICNIC (Pediatric Investigators Collaborative Network on Infections in Investigators Collaborative Network on Infections in
Canada) study of the role of age and respiratory syncytial virus neutralizing antibody on respiratory syncytial virus illness in patients with underlying heart or lung disease. Pediatrics 1997;99:e9.

13 Nachman SA, Navaie-Waliser M, Qureshi MZ. Rehospitalization with respiratory syncytial virus after neonatal intensive care unit discharge: a 3-year follow-up. Pediatrics 1997; 100: 8 .

14 Joffe S, Escobar GJ, Black SB, et al. Rehospitalization for respiratory syncytial virus among premature infants. respiratory syncytial virus

15 Allport TD, Davies EG, Wells C, et al. Ribavarin and bronchiolitis: variation in use in the UK. Arch Dis Child 1997;76:385.

16 Hall CB, Stevens TP, Swantz RJ, et al. Development of local guidelines for prevention of respiratory syncytial viral infections. Pediatr Infect Dis F 1999;18:850-3.

17 Marchetti A, Lau H, Magar R, et al. Impact of palivizumab on expected costs of respiratory syncytial virus infection in preterm infants: potential for savings. Clin Ther 1999;21: 752-66.

18 Joffe S, Ray GT, Escobar GJ, et al. Cost-effectiveness of respiratory syncytial virus prophylaxis among preterm infants. Pediatrics 1999;104:419-27.

19 Moler FW. RSV immune globulin prophylaxis: is an ounce of prevention worth a pound of cure. Pediatrics 1999;104: 559-60. 